\title{
Application of Non Pneumatic Anti- Shock Garment (NASG) in 100 patients of postpartum haemorrhage: analysis of causes, management and outcome in a tertiary centre of south Rajasthan
}

\author{
Kulshreshtha S. ${ }^{1}$, Jain P. ${ }^{2}$ \\ ${ }^{1}$ Dr. Shabdika Kulshreshtha, Assistant Professor, ${ }^{2}$ Dr. Payal Jain, Associate Professor, Department of Obstetrics \& \\ Gynaecology; both authors are affiliated with Ananta Institute of Medical Sciences, Rajsamand, Rajasthan, India. \\ Corresponding Author: Dr. Payal Jain, Associate Professor, Department of Obstetrics \& Gynaecology, Ananta Institute \\ of Medical Sciences, Rajsamand, Rajasthan, India. Corresponding Address: 36, Anand Nagar, Near Ayad Bridge, \\ University Road, Udaipur. Email: dr.shikha9983@gmail.com
}

\begin{abstract}
Objectives: The present study was performed to assess the role of NASG (non pneumatic anti shock garment) in the management of postpartum haemorrhage. Material and Methods: The present study is a retrospective study carried out in the department of Obstetrics \& Gynaecology of a tertiary care institute of southern Rajasthan during the period of six years from July 2009 to June 2015. 100 patients of postpartum haemorrhage (PPH) with gestational age $\geq 28$ weeks were included in the study. All the patients delivered at our institute and BMI $\sim 18.5-24.9 \mathrm{~kg} / \mathrm{m}^{2}$ so that NASG was meticulously applied. Results: 100 patients of PPH were included in present study and NASG were applied to them. Age of the patients ranged from 18 to 45 years with the mean age of 25.99 years. $13 \%$ of the patients were grand multipara while $20 \%$ patients were primi and remaining $63 \%$ were multipara. The most common cause of PPH was atonic uterus (77\%), of which commonest etiology was maternal anaemia (37.6\%). Next common cause was trauma of genital tract $(19 \%)$ out of which vaginal injuries were the most common $(47.36 \%)$. Other rare causes were tissue factor $(3 \%)$ and coagulopathies (1\%).67\% of the study participants had normal delivery while $29 \%$ patients had caesarian sections and remaining(4\%) had instrumental delivery. After NASG application, 53\% patients responded to medical management, $32 \%$ were managed surgically and rests $15 \%$ were stabilized by manoeuvres. $57 \%$ patients stayed for three days in the hospital while $29 \%$ stayed for five days. Only $3 \%$ patients had a hospital stay of $\geq$ six days. Conclusion: The present study concluded that majority of patients suffering from PPH were multigravidas in the reproductive age group of 21-30 years. The major cause of PPH was uterine atony followed by genital tract injuries. Use of NASG in these patients significantly reduced any major surgical intervention. Most of these patients were successfully managed by uterotonics, blood components and supportive care. Even a substantial decrease in theduration of stay in hospital and ICU stay was noted.
\end{abstract}

Keywords: Postpartum haemorrhage, Non-pneumatic anti-shock garment, Maternal mortality, Multigravidas

\section{Introduction}

Postpartum haemorrhage $(\mathrm{PPH})$ is one of the most dreadful nightmares for an obstetrician. Unfortunately, each one of us has experienced it sooner or later. It is the most frequently asked topic for viva voce and various other assessments. It is also most common cause of maternal mortality in India and worldwide. Sarcastically speaking, oneof the Seven Wonders of the world- The TAJ was built only because of PPH. Such is the magnitude of PPH, so it is our duty to prevent and predict this multifaceted monster in disguise.

Manuscript received: $10^{\text {th }}$ July 2019

Reviewed: $20^{\text {th }}$ July 2019

Author Corrected: $27^{\text {th }}$ July 2019

Accepted for Publication: $1^{\text {st }}$ August 2019

Obsgyne Review: Journal of Obstetrics and Gynecology
PPH is defined as:

I) Quantitative definition -the amount of blood loss in excess of $500 \mathrm{ml}$.

II) Clinical definition-any amount of bleeding from or into the genital tract following birth of the baby upto the end of the puerperium, which adversely affects the general condition of the patient evidenced by rise in pulse rate and falling blood pressure[1].

PPH is of two types-primary, secondary. Primary is more common occurring within 24 hours following the child birth while secondary occurs after 24 hours up to 
12 weeks [1]. Every day, around 830 women die from pregnancy or childbirth-related complications worldwide. Almost $52 \%$ of maternal mortality is due to these three causes-haemorrhage, sepsis, and hypertensive disorders. As per WHO $25 \%$ of maternal mortality is contributed by $\mathrm{PPH}$. Incidence of $\mathrm{PPH}$ varies from $2 \%$ $4 \%$ following vaginal delivery and $6 \%$ post operatively (cesarean section). Around $50 \%$ cases of $\mathrm{PPH}$ are attributed to uterine atony. [2].

The causes of PPH are classified as 4 Ts:

- Tone:uterine atony due to overdistention, exhaustion or retained products.

- Trauma:cervical/vaginal/perineal tears rupture uterus.

- Tissue:retained placenta (normal/abnormal)

- Thrombin:intrauterine death, amniotic fluid embolism, disseminated intravascular coagulation (DIC) [3]

PPH is like a rolling stone. The catastrophe of events leading to shock and death are quite speedy; therefore even a timely referral from peripheries can be fatal. So a device like NASG (non pneumatic anti shock garment) can be of immense help while referring from peripheral (primary/secondary) health centre as well as commencing the definitive therapy at the tertiary centre. The time of revival can then be lengthened so as to save the patient's life.

NASG is a non pneumatic anti shock garment. As the name suggests, it overcomes the disadvantages of pneumatic ones (like compartment syndrome, acidosis, compromising renal perfusion). It is FDA approved counter pressure garment which is made up of three way stretch neoprene with Velcro fasteners and a soft abdominal ball for uterine compression. It is designed in such a manner so that it is easily applied and requires minimal skill. It maintains a pressure of $20-40 \mathrm{~mm}$ of $\mathrm{Hg}$ so that hemostasis is adequately maintained without ischaemia. This range of pressure causes no discomfort to the patients. It is hassle free due to absence of tubings, cuffs, bladders. It can be easily cleaned by using bleaching powder solution. This quality even makes it easy to maintain, inexpensive and free from risk of over inflation. [4]

Application of NASG causes compression of peripheral vessels and diverts the flow to the vital organs. Thus there is translocation of the blood reducing total vascular volume while expanding the central circulation. It also has a tamponade effect on splanchnic plexus thereby reducing the bleeding[5].
Contraindications of NASG are pregnant patients with live fetus, pulmonary hypertension, congestive heart failure, mitral stenosis, supra diaphragmatic bleeding [6].

\section{Material and Methods}

The present study is a retrospective study carried out in the Department of Obstetrics \& Gynaecology, R.N.T Medical College, Udaipur for six years from July 2009 to June 2015

Setting: Tertiary care

Type of study: Retrospective longitudinal study

Participants: In the present study, 100 patients of postpartum haemorrhage with gestational age $\geq 28$ weeks were included.

All the patients delivered at our institute and BMI $\sim 18.5-24.9 \mathrm{~kg} / \mathrm{m}^{2}$ so that NASG was meticulously applied.These patients were chronologically selected as per date of admission fitting the inclusion criteria.

Type of participants: All 100 patients were evaluated in terms of their demographic profile, causes of postpartum haemorrhage, management and their maternal outcome. All the patients/attendants included in the study gave written informed consent.

It was ensured that their personal details including obstetric history would remain confidential.

Inclusion Criteria-All the patients of postpartum haemorrhage (whether in shock or not) were included.

The causes were divided into following categories viz.

- Tone- atonic due to

Grand multipara: A pregnant female with previous 4 or more viable births

Multifetal pregnancy: Twins, triplets and so on

Polyhydramnios: As per ultrasonography, single largest pocket of vertical length more than $8 \mathrm{~cm}$ or the $\mathrm{AFI}>20$.

Macrosomia: birth weight $>3500$ or $4000 \mathrm{~g}$ (large for gestational age with a birth weight greater than the $90^{\text {th }}$ percentile of the expected weight.

Maternal Anaemia: $\mathrm{Hb}<11 \mathrm{gm} \%$

Accidental haemorrhage: including Placenta praevia and Abruptio placentae

Others: including uterine malformations, fibroid uterus, chorioamnionitis, and full bladder. 
- Trauma: Rupture uterus, cervical, vaginal, perineal tears

- Tissue: Retention of clots, placenta (normal/ abnormal like accrete, percreta, increta, succenturiate lobe)

- Thrombin: Disseminated intravascular coagulation (DIC), amniotic fluid embolism and fetal death.

Obstetric outcome was studied in terms of

1. Mode of delivery ie normal, operative, instrumental delivery.

2. Post NASG (non pneumatic anti shock garment) intervention viz.

a) Medical management - uterotonics, (oxytocin, methylergometrine, $\mathrm{PGF}_{2}$ alpha, $\mathrm{PGE}_{1}$, intravenous fluids,blood and blood products transfusion, vitamin $\mathrm{K}$, tranexamic acid).

b) Manoeuvres -balloon tamponade (condoms, surgical gloves)

c) Surgical management -repair of tears, compression sutures (modified B Lynch), arterial ligation (uterine, internal iliac), hysterectomy (subtotal/total).

\section{Original Research Article}

3. ICU admission

4. Hospital stay

Demographic profiles such as age, parity, were also taken into account.

\section{Exclusion criteria}

1. Pregnancy with gestation $<28$ weeks of gestation.

2. Antepartum haemorrhage due to abortion (spontaneous/medical) ,ectopic pregnancy, molar pregnancy, varices, ectropion, erosions or any local pathologies.

3. Underweight pts with $\mathrm{BMI}<18.5 \mathrm{~kg} / \mathrm{m}^{2}$, overweight patients with $\mathrm{BMI}>25 \mathrm{~kg} / \mathrm{m}^{2}$ were excluded as NASG was available in medium size at our institute.

4. Cases of $\mathrm{PPH}$ with uterine inversion were not included.

5. Patients unwilling for NASG application were also not included in the study.

\section{Results}

100 patients delivered institutionally who suffered from PPH followed by NASG application during the given study period of six years from July 2009 to June 2015 were included in the study. All these patients matched the inclusion criteria and were included in chronological order of their date /time of admission.

In the present study, age of patients ranged from 18 to 45 years with the mean age of 25.99 years. $13 \%$ of the patients were grand multipara while $20 \%$ patients were primi and remaining $63 \%$ were multipara. Table 1,2 describe the demographic profile and obstetric history of the patients included in the present study

Table-1: Agewise distribution of patients.

\begin{tabular}{|c|c|c|}
\hline Age(in years) & No. of patients & Percentage \\
\hline$\leq 20$ & 16 & 16 \\
\hline $21-30$ & 63 & 63 \\
\hline$>30$ & 21 & 21 \\
\hline Total & $\mathbf{1 0 0}$ & $\mathbf{1 0 0}$ \\
\hline
\end{tabular}

Table-2: Distribution of parity.

\begin{tabular}{|c|c|c|}
\hline Parity & No. of patients & Percentage \\
\hline Primi & 20 & 20 \\
\hline $2-4$ & 67 & 67 \\
\hline$>4$ & 13 & 13 \\
\hline Total & $\mathbf{1 0 0 \%}$ & $\mathbf{1 0 0}$ \\
\hline
\end{tabular}

The most common cause of PPH was atonic uterus (77\%), of which commonest etiology was maternal anaemia (37.6\%). Next common cause was trauma of genital tract (19\%) out of which vaginal injuries were the most common (47.36\%). Other rare causes were tissue factor $(3 \%)$ and coagulopathies (1\%). Table 3 
Table-3: Distribution of causes of PPH.

\begin{tabular}{|c|c|c|}
\hline \multicolumn{3}{|l|}{ Sub-distribution as per tone of uterus } \\
\hline Tone & No. of patients & Percentage \\
\hline Grand multipara & 11 & 14.2 \\
\hline Multifetal pregnancy & 7 & 9.09 \\
\hline Polyhydramnios & 3 & 3.89 \\
\hline Macrosomia & 5 & 6.49 \\
\hline Maternal anaemia & 29 & 37.6 \\
\hline Accidental haemorrhage & 19 & 24.6 \\
\hline $\begin{array}{l}\text { Others (uterine malformations, fibroid, } \\
\text { chorioamnionitis, full bladder) }\end{array}$ & 3 & 3.89 \\
\hline Total & 77 & 100 \\
\hline \multicolumn{3}{|l|}{ Sub-disrtibution as per trauma } \\
\hline Trauma & No. of patients & Percentage \\
\hline Rupture uterus & 3 & 15.78 \\
\hline Cervical tear & 4 & 21.05 \\
\hline Vaginal tear & 9 & 47.36 \\
\hline Perineal tear & 3 & 15.78 \\
\hline Total & 19 & 100 \\
\hline \multicolumn{3}{|c|}{ Sub-distribution as per tissue factor (retained products/placenta) } \\
\hline Tissue & No. of patients & Percentage \\
\hline
\end{tabular}

\begin{tabular}{|l|c|c|}
\hline Retention of Clots/placenta & 2 & 66.6 \\
\hline Abnormal Placentation & 1 & 33.3 \\
\hline Total & $\mathbf{3}$ & $\mathbf{1 0 0}$ \\
\hline Sub-distribution as per thrombin (coagulopathy) & No, of patients \\
\hline Thrombin & 0 & Percentage \\
\hline DIC amniotic fluid & 1 & 0 \\
\hline $\begin{array}{l}\text { Others (fetal deaths, } \\
\text { embolism) }\end{array}$ & $\mathbf{1}$ & $\mathbf{1 0 0}$ \\
\hline Total & & \\
\hline
\end{tabular}

$67 \%$ of the study participants had normal delivery while $29 \%$ patients had caesarean sections and remaining(4\%) had instrumental delivery (instrumental or forceps delivery)(Table 4)

Table-4: Distribution of Mode of delivery

\begin{tabular}{|c|c|c|}
\hline Mode & No. of patients & Percentage \\
\hline Normal & 67 & 67 \\
\hline Instrumental & 4 & 4 \\
\hline Operative & 29 & $\mathbf{1 0 0}$ \\
\hline Total & $\mathbf{1 0 0}$ & 29 \\
\hline
\end{tabular}

After NASG application, 53\% patients responded to medical management, 32\% were managed surgically and rests $15 \%$ were stabilized by manoeuvres. (Table 5). 
Table-5: Distribution of post NASG intervention.

\begin{tabular}{|c|c|c|}
\hline Intervention & No. Of patients & Percentage \\
\hline Medical & 53 & 53 \\
\hline Manoeuvres & 15 & 15 \\
\hline Surgical & 32 & 32 \\
\hline Total & $\mathbf{1 0 0}$ & $\mathbf{1 0 0}$ \\
\hline
\end{tabular}

$57 \%$ patients stayed for three days in the hospital while $29 \%$ stayed for five days. Only $3 \%$ patients had a hospital stay of $\geq$ six days and $11 \%$ stayed for four days. (Table 6 )

Table-6: Hospital stay of the study participants

\begin{tabular}{|c|c|c|}
\hline No. of days & No. of patients & Percentage \\
\hline 3 & 57 & 57 \\
\hline 4 & 11 & 29 \\
\hline 5 & 29 & 3 \\
\hline$\geq 6$ & 3 & $\mathbf{1 0 0}$ \\
\hline Total & $\mathbf{1 0 0}$ & 11 \\
\hline
\end{tabular}

Out of 100 patients, only 43 patients had ICU stay. Among these, $67.44 \%$ patients stayed in ICU for two days, $25.58 \%$ stayed for eleven days, $6.97 \%$ patients stayed for $\geq$ three days.

Table-7: Distribution of ICU stay

\begin{tabular}{|c|c|c|}
\hline No. of days & No. of patients & Percentage \\
\hline 1 & 11 & 25.58 \\
\hline 2 & 29 & 67.44 \\
\hline$\geq 3$ & 3 & 6.97 \\
\hline Total & $\mathbf{4 3}$ & $\mathbf{1 0 0}$ \\
\hline
\end{tabular}

\section{Discussion}

In the present study, majority of the patients $(63 \%)$ were in the age group 21-30 years, followed by $21 \%$ in the age group $>30$ years. $16 \%$ patients were less than 20 years of age. Similar studies done in the past had similar findings.

This is due to the fact that reproductive potential is highest in this age group in India. In a study by Oladosu A et al in 2010 mean age of patients in NASG application group was 30.2 years [7]. As per another study by Kodla C S et al in 2015, $83.47 \%$ patients of $\mathrm{PPH}$ were in the age group of 21-30 years[8].

Another study by Escobar M F et al in 2017 found that mean age of the study subjects was $25 \pm 6$ years in a similar study [9]. Bangal VB et al in 2019 also observed $60 \%$ patients were in the age group of $20-30$ years. [10].
Considering the obstetric history, $67 \%$ patients are multipara, $20 \%$ primi and rest $13 \%$ are grand multipara in the present study. It can be observed here that both multipara and grand multipara account for $\sim 70 \%$ of cases of PPH.

This is quite significant as it is itself a risk factor for atonic PPH. In another similar study by Oladosu A et al in 2010, mean parity of study subjects was 5.7 [7].

A PPH related study by Kodla C S et al in 2015 also observed that $65.07 \%$ cases were primarily multipara and grand multipara[8]. Escobar M F et al in 2017 found that while $52 \%$ patients were primi, remaining $48 \%$ were multipara and grandmultipara[9]. One more study by Bangal VB et al in 2019 observed that $84 \%$ patients were multipara and grandmultipara [10]. 


\section{Original Research Article}

In the present study, the most common cause of $\mathrm{PPH}$ was atonic uterus $(77 \%)$, of which commonest etiology was maternal anaemia (37.6\%). Next common cause was trauma of genital tract $(19 \%)$ out of which vaginal injuries were the most common $(47.36 \%)$. Other rare causes were tissue factor (retained products/placenta) $(3 \%)$ and coagulopathies (1\%). In a study by Oladosu A et al in 2010 , uterine atony (42\%) was the leading cause followed by tissue factor (retained products/placenta) (36.2\%). Genital tract trauma accounted for $20.7 \%$ [7].

Another study by Sutherland T. et al in 2013 stated that with NASG application top three definitive diagnosis in Egypt were uterine atony (44\%), abortion related complications, ectopic pregnancy $(13 \%)$ while in Nigeria were uterine atony (26\%), retained placenta (23\%), placental abruption(17\%) [11]. As per another study by Kodla C S et al in 2015, uterine atony (33.91\%), abruption (22.6\%) and placenta praevia $(16.52 \%)$ were the leading causes of PPH.

Genital tract trauma (4.34\%) was the least common. [8] Another study by Escobar M F et al in 2017 studied that major etiology was uterine atony $(96 \%)$, retained products /placenta $(15 \%)$, vaginal tears $(6 \%)$, placenta praevia (5\%). (9) A study by Bangal VB et al in 2019 observed that atonic PPH occurred in $77.7 \%$ of patients while remaining had traumatic PPH [10].

In the present study, $67 \%$ of the participants had normal delivery while $29 \%$ patients had caesarean sections and remaining (4\%) had instrumental delivery (instrumental or forceps delivery). In a study by Kodla C S et al in $2015,55.65 \%$ patients delivered by caesarean section and $40.86 \%$ had vaginal delivery[8]. Another study by Escobar M F et al in 2017 found that 69\% patients delivered vaginally while $13 \%$ had induced delivery[9]. Bangal VB et al in 2019 noted that by the time NASG was applied 56\% patients delivered[10].

The present study demonstrated that after NASG application, 53\% patients responded to medical management, $32 \%$ were managed surgically and rest $15 \%$ were stabilized by manoeuvres. This further reiterates that NASG application increases the success rate of medical intervention. In a study by Oladosu A et al in 2010 it was observed that in pts where NASG was applied, 91.4\% required uterotonics; $59.8 \%$ were infused with crystalloids; $83.3 \%$ were transfused with blood[7]. Another study by Sutherland T. et al in 2013 demonstrated that use of NASG decreased the unit of blood transfusion by $75 \%$ in Egypt and $4 \%$ in Nigeria; uterotonic units were again decreased to $9 \%$ in
Egypt and 25\% in Nigeria; hysterectomy was significantly lowered by $59 \%$ in Egypt whereas very few hysterectomies were performed in Nigeria[11] In a study by Kodla C S et al in 2015 , data on post PPH interventions was as follows-23.33\% devascularisation, $25.56 \%$ hysterectomy, $87.78 \%$ massive transfusion, $3.74 \%$ internal artery ligation, $7.82 \%$ uterine artery embolisation [8]. Another study by Escobar M F et al in 2017 found that $70 \%$ patients received an intrauterine tamponade with Bakri balloon, $10 \%$ underwent B lynch surgery, $2.59 \%$ were taken for hysterectomy while $40.6 \%$ had blood transfusion[9]. Bangal VB et al in 2019 noted that in $92 \%$ patients where NASG was applied along with medical management shock index rapidly improved to $0.5-0.9[10]$.

In the present study, 57\% patients stayed for three days in the hospital while 29\% stayed for five days. Only 3\% patients had a hospital stay of $\geq$ six days and $11 \%$ stayed for four days. Out of 199 patients only 43 patients had ICU stay. Among these, $67.44 \%$ patients stayed in ICU for two days, $25.58 \%$ stayed for eleven days, $6.97 \%$ patients stayed for $\geq$ three days. Quite a few studies were available to evaluate the post NASG hospital and ICU stays. Nevertheless, Escobar M F et al in 2017 found that patients were hospitalized for a median of 4 days while remained for 3 days in ICU[9] Still few studies commented on morbidity and mortality. Oladosu A et al in 2010 reported that rate of mortality was nil in NASG group with mean arterial pressure (MAP) $>60 \mathrm{~mm}$ of $\mathrm{Hg}$ while it was $7.5 \%$ in patients with $\mathrm{MAP}<60$ [7]. Another study by Sutherland $\mathrm{T}$ et al in 2013 observed that morbidity rates with NASG were $0.9 \%$ and $0.4 \%$ whereas mortality rates were $1.1 \%$ and $8.7 \%$ in Egypt and Nigeria respectively [11].

According to a study on PPH by Kodla C S et al in 2015 , morbidity was seen in $78.26 \%$ cases while $21.73 \%$ had mortality with conventional management [8]. Bangal VB et al in 2019 reported that $4 \%$ patients expired even after NASG application [10]. Another study by Sharma et al in 2016 noted that annual average of maternal deaths due PPH were one and two respectively in the districts of Gaya and Purniya. However in Gurua block of Gaya district NASG was applied to save two patients of $\mathrm{PPH}[12]$. According to a systemic review by Pileggi-Castro et al in 2015, in five observational studies, there were 46 maternal deaths with NASG as against 72 with the standard line of treatment. As per the sixth cluster randomized control trial, 4 deaths were in NASG group as compared to 11 deaths in the other one[13]. 
Original Research Article

\section{Conclusion}

The present study concluded that majority of patients suffering from $\mathrm{PPH}$ were multigravida in the reproductive age group of 21-30 years.

The major cause of PPH was uterine atony followed by genital tract injuries. Use of NASG in these patients significantly reduced any major surgical intervention.

Most of these patients were successfully managed by uterotonics, blood components and supportive care.

Even a substantial decrease in the duration of stay in hospital and ICU stay was noted. The best part of the study is that NASG is a simple device which can be used by a pre-sensitized minimally trained healthcare worker. Still I emphasize that preventive measures like mock drills of PPH with NASG application are needed to combat this multiheaded monster( $\mathrm{PPH})$.

Our country should realize the cost effectiveness of its prophylaxis. However, PPH being multifactorial in etiology continues to haunt the obstetricians.

Limitations- The limitations of this study are

1) The sample size can be increased and the sample collection could be multicentric so that generalizability of the study increases.

2) The maternal blood loss can be quantified after NASG application.

3) The study design could be comparative to assess outcome with/without NASG.

\section{What the study adds to the existing knowledge?}

NASG is life saving and cost effective measure in managing PPH particularly in a low resource setup in South Rajasthan.

This study reiterates that early application of NASG reduced the need of blood products, surgery, post operative hospital and ICU stay.

\section{Author'scontribution}

Dr. ShabdikaKulshreshtha:Study concept and design, revision and proof.

Dr. Payal Jain:Data analysis; Statistics, drafting;

Funding: Nil, Conflict of interest: Nil

Permission from IRB: Yes

\section{References}

1. Dutta D C, Text book of Obstetrics. New Central book Agency (P) Ltd, Calcutta, India. 2015

2. Rastogi A,Post partumhaemorrage.http://www.nhp. gov. in/disease/gynaecology- and -obstetrics / postpartum- haemorrhage. 2017

3. Holland \& Brews, Manual of Obstetrics. Reed Elsevier India (P) Ltd, 2016, New Delhi, India.

4. Hensleigh PA. Anti-shock garment provides resuscitation and haemostasis for obstetric haemorrhage.BJOG. 2002;109(12):1377-84. doi: https:// doi. org/10. 1046/j.1471-0528.2002.02197.x

5. Miller S, Martin HB, Morris JL. Anti-shock garment in postpartum haemorrhage. Best Pract Res Clin Obstet Gynaecol. 2008;22(6):1057-74. doi: 10.1016/j.bpobgyn. 2008.08.008. Epub 2008.

6. Penn AW, Beam NK, Azman H, Kellie FJ. Non-pneumatic anti-shock garment (NASG) as a first aid for preventing or reversing hypovolemic shock secondary to obstetric hemorrhage. The Cochrane database of systematic reviews. 2018;2018(2). doi: 10. 1002/14651858.CD011700

7. Ojengbede OA, Morhason-Bello IO, Galadanci H, Meyer C, Nsima D, Camlin C, et al. Assessing the role of the non-pneumatic anti-shock garment in reducing mortality from postpartum hemorrhage in Nigeria. Gynecol Obstet Invest. 2011;71(1):66-72. doi: 10. 1159/ 000316053. Epub 2010.

8. Kodla CS. A study of prevalence, causes, risk factors and outcome of severe obstetrics haemorrhage. J Sci Innovative Res. 2015;4(2):83-7.

9. Escobar MF, Füchtner CE, Carvajal JA, Nieto AJ, Messa A, Escobar SS, et al. Experience in the use of non-pneumatic anti-shock garment (NASG) in the management of postpartum haemorrhage with hypovolemic shock in the Fundación Valle Del Lili, Cali, Colombia. Reprod Health. 2017;14(1):58. doi: 10. 1186/s12978-017-0325-2.

10. Bangal B V,Gavhane S, Raut S,ThoratU.Use of non-pneumatic anti shock garment in hemorrhagic shock. Int J Reprod Contracept Obstet Gynecol. 2019; 8(2): 621-627.doi: http://dx.doi.org/10.18203/ 23201770. ijrcog20190295 
11. Sutherland T, Downing J, Miller S, Bishai DM, Butrick E, Fathalla MM, et al. Use of the nonpneumatic anti-shock garment (NASG) for lifethreatening obstetric hemorrhage: a cost-effectiveness analysis in Egypt and Nigeria. PLoS One. 2013; 8 (4): e62282. doi: 10.1371/journal. pone. 0062282. Print 2013.

12. Sharma J, Negandhi P, Das AM, Sethy G, Neogi $\mathrm{SB}$, Ali SH. Using nonpneumatic anti-shock garment for postpartum hemorrhage management and referral at the public health facilities: A pilot study in two districts of Bihar. Indian J Public Health. 2016;60 (4):316322. doi: 10.4103/0019-557X.195866.

13. Pileggi-Castro C, Nogueira-Pileggi V, Tunçalp Ö, Oladapo OT, Vogel JP, Souza JP. Non-pneumatic anti-shock garment for improving maternal survival following severe postpartum haemorrhage: a systematic review. Reprod Health. 2015;31;12:28. doi: 10.1186/ s12978-015-0012-0.

\section{How to cite this article?}

Kulshreshtha S, Jain P. Application of Non Pneumatic Anti- Shock Garment (NASG) in 100 patients of postpartum haemorrhage: analysis of causes, management and outcome in a tertiary centre of southRajasthan. Obs Rev: $J$ obstet Gynecol 2019;5(3):133-140.doi:10.17511/joog.2019.i03.02. 